\title{
XÁC ĐỊNH LƯợNG BỐC THOÁT NƯỚC THỰC TẾ TẠI LƯU VỰC SÔNG CẦU BẦNG Ú'NG DỤNG TƯ LIỆU ẢNH LANDSAT
}

\author{
NGUYẼN VĂN HÙNG
}

Cục Viễn thám Quốc gia

\section{Tóm tắt:}

Bốc thoát hơi nước bề mặt đất ET (evapotranspiration) là quá trình chuyển đổi khối lượng nước từ bề mặt (đất) thành hơ nước (bốc hoii) và từ thảm thực vật (thoát hơ nước) vào bầu không khí. Với sự phát triển của công nghệ viễn thám, trong những năm gần đây các nhà nghiên cứu trên thế giới đang từng bước ứng dụng công nghệ viễn thám để xác định lượng bốc thoát hơ nước thực tế ETa, giảm đáng kể về chi phí và công sức cho công tác quan trắc ngoại nghiệp.

Bài báo giới thiệu ứng dụng phương pháp Chỉ số cân bằng năng lượng bức xạ bề mặt đơn giản (Simple Surface Energy Balance Index) [7] ước tính lượng bốc thoát hơ nước thực tế ETa (mm/ngày) tại lưu vực Sông Cầu với việc sử dụng ảnh Landsat.

\section{1. Đặt vấn đề}

Hiện tượng bốc thoát hơi nước $(E T)$ đã từ lâu được công nhận là quá trình quan trọng và đóng một vai trò thiết yếu trong việc trao đổi năng lượng và khối lượng giữa thủy quyển, khí quyển và sinh quyển. Bốc thoát hơi nước bề mặt đất ET (evapotranspiration) là quá trình chuyển đổi khối lượng nước từ bề mặt (đất) thành hơi nước (bốc hơi) và từ thảm thực vật (thoát hơi nước) vào bầu không khí. Ước tính $\mathrm{ETa}$ thực tế rất quan trọng trong mô hình cân bằng nước ở các lưu vực sông, phục vụ công tác quản lý tưới tiêu trong nông nghiệp và trong dự báo thời tiết. Nhưng rất khó để đo lường $\mathrm{ETa}$ trực tiếp và trong hầu hết các ứng dụng, ETa được ước tính bằng cách sử dụng các mô hình lý thuyết-thực nghiệm. Độ tin cậy định lượng ET không chỉ là một nhiệm vụ quan trọng cho các nhà quản lý nguồn tài nguyên nước, mà còn là một thách thức đối với các nhà khoa học.

Với sự phát triển của công nghệ viễn thám, trong những thập kỷ gần đây các nhà nghiên cứu trên thế giới đang từng bước ứng dụng công nghệ viễn thám để ước tính lượng bốc thoát hơ nước thực tế ETa, giảm đáng kể về chi phí và công sức cho công tác quan trắc ngoại nghiệp. Bài báo giới thiệu ứng dụng ảnh viễn thám Landsat-7 ước tính lượng bốc thoát hơi nước thực tế $\mathrm{ETa}$ (mm/ngày) sử dụng phương pháp Chỉ số cân bằng năng lượng bức xạ bề mặt đơn giản (Simple Surface Energy Balance Index) [7] tại lưu vực Sông Cầu với sai số tuyệt đối trung bình theo phần trăm MAE là $13,29 \%$ và sai số trung phương RMSE là $0.55(\mathrm{~mm} / \mathrm{ngày})$ của ngày $23 / 11 / 2001$ và sai số tuyệt đối trung bình theo phần trăm MAE là $19,27 \%$ và sai số trung phương RMSE là $0.92(\mathrm{~mm} / \mathrm{ngày})$ của ngày $04 / 11 / 2000$.

\section{Khu vực nghiên cứu và dữ liệu}

\subsection{Khu vực nghiên cứu}

Lưu vực Sông Cầu nằm trong phạm vi tọa độ địa lý: $21^{\circ} 07^{\prime}-22^{\circ} 18^{\prime}$ vĩ bắc, $105^{\circ} 28^{\prime}$ - 1060. kinh đông, diện tích lưu vực khoảng $6030 \mathrm{~km}^{2}$. Lưu vực chiếm khoảng $47 \%$ diện tích toàn vùng, bao gồm toàn bộ hay một phần lãnh thố của các tỉnh Bắc Kạn, Thái Nguyên, Bắc Ninh, Bắc Giang,

Ngày nhận bài: 07/11/2016, ngày chuyển phản biện: 10/11/2016, ngày chấp nhận phản biện: 29/11/2016, ngày chấp nhận đăng: 05/12/2016 
Vĩnh Phúc và Hà Nội. Sông Cầu là dòng chính của hệ thống sông Thái Bình, bắt nguồn từ vùng núi Phia Đeng $(1527 \mathrm{~m})$ ở sườn đông nam của dãy Pia-bi-óc. Dòng chính Sông Cầu chảy qua các tỉnh Bắc Cạn, Thái Nguyên, Bắc Giang, Bắc Ninh rồi đổ vào sông Thái Bình tại Phả Lại.

\subsection{Dữ liệu đầu vào}

- Dữ liệu ảnh Landsat 7 ETM chụp ngày $04 / 11 / 2001$ và ngày $23 / 11 / 2001$ mức xử lý 1T, path, row 126/45 không mây.

- Mô hình số độ cao (DEM) tại Lưu vực Sông Cầu được thành lập từ bản đồ địa hình tỷ lệ $1 / 25.000$ đã đưa về cùng độ phân giải 30×30m.

- Số liệu đo đạc tại các trạm quan trắc ngoài thực địa gồm: nhiệt độ, vận tốc gió, số giờ nắng thực, độ ẩm không khí và bốc hơi nước của 06 trạm khí tượng thuỷ văn tại lưu vực Sông Cầu (xem bảng 1, bảng 2).

\section{Phương pháp ứng dụng}

3.1. Phương pháp chiết tách năng Iượng bức xạ mặt trời trung bình ngày Rnd

Theo Bastiaanssen, et al. 1996 [1,2] bức xa ròng tại thời điểm $i$ thu nhận ảnh được chiết xuất từ ảnh dựa trên nguyên lý cân bằng năng lượng bức xạ bề mặt $R_{n i}$ được

Bảng 1: Các số liệu đo đạc tại 06 điểm quan trắc ở ngoại nghiệp thời điểm ngày 04/11/2000

\begin{tabular}{|c|c|c|c|c|c|c|c|c|c|}
\hline \multirow[t]{2}{*}{ Trạm quan trắc } & \multicolumn{2}{|c|}{ Tọa độ } & \multirow{2}{*}{$\begin{array}{c}\mathrm{Z} \\
(\mathrm{m})\end{array}$} & \multicolumn{2}{|c|}{$\begin{array}{c}\text { Nhiệt độ } \\
\text { không khí }\left({ }^{\circ} \mathrm{C}\right)\end{array}$} & \multirow{2}{*}{$\begin{array}{l}\text { Vấn } \\
\text { tốc } \\
\text { gió } \\
(\mathrm{m} / \mathrm{s})\end{array}$} & \multirow[t]{2}{*}{\begin{tabular}{|c|} 
Giờ' \\
nắng thực \\
(giờ)
\end{tabular}} & \multirow{2}{*}{$\begin{array}{c}\text { Độ ẩm } \\
\text { không } \\
\text { khí } \\
(\%)\end{array}$} & \multirow[t]{2}{*}{$\begin{array}{c}\text { Bốc hơi } \\
\text { nước } \\
\text { (mm/ngày) }\end{array}$} \\
\hline & $B$ & $\mathrm{~L}$ & & $\mathrm{~T}_{\min }$ & $\mathrm{T}_{\max }$ & & & & \\
\hline 1 & \multicolumn{2}{|c|}{2} & 3 & \multicolumn{2}{|c|}{4} & 5 & 6 & 7 & 8 \\
\hline 1. Bắc Ninh & $21^{0} 11$ & $106^{\circ} 05^{\prime}$ & 3 & 13.8 & 27.3 & 4 & 9.9 & 70 & 4.9 \\
\hline 2. Bắc Giang & $21^{0} 17$ & $106^{0} 12^{\prime}$ & 7 & 13.3 & 28.0 & 4 & 9.8 & 72 & 3.9 \\
\hline 3. Vĩnh Yên & $21^{0} 19$ & $105^{\circ} 36^{\prime}$ & 17 & 14.8 & 27.7 & 5 & 10.0 & 76 & 3.1 \\
\hline 4. Tam Đảo & $21^{\circ} 28$ & $105^{\circ} 39^{\prime}$ & 685 & 12.2 & 22.2 & 6 & 10.1 & 54 & 4.3 \\
\hline 5.Thái Nguyên & $21^{0} 36$ & $105^{\circ} 50^{\prime}$ & 36 & 13.2 & 28.6 & 4 & 10.4 & 73 & 4.4 \\
\hline 6. Bắc Kạn & $22^{\circ} 09$ & $105^{\circ} 50^{\prime}$ & 138 & 11.1 & 28.8 & 4 & 8.7 & 79 & 2.8 \\
\hline
\end{tabular}

Bảng 2: Các số liệu đo đạc tại 06 điểm quan trắc ở ngoại nghiệp thời điểm ngày 23/11/2001

\begin{tabular}{|c|c|c|c|c|c|c|c|c|c|}
\hline \multirow[t]{2}{*}{ Trạm quan trắc } & \multicolumn{2}{|c|}{ Tọa độ } & \multirow{2}{*}{$\begin{array}{c}\mathrm{Z} \\
(\mathrm{m})\end{array}$} & \multicolumn{2}{|c|}{$\begin{array}{c}\text { Nhiệt độ } \\
\text { không khí }\left({ }^{\circ} \mathrm{C}\right)\end{array}$} & \multirow{2}{*}{$\begin{array}{c}\text { Vận } \\
\text { tốc } \\
\text { gió } \\
(\mathrm{m} / \mathrm{s})\end{array}$} & \multirow[t]{2}{*}{\begin{tabular}{|c|} 
Giờ \\
nắng thực \\
(giờ)
\end{tabular}} & \multirow{2}{*}{$\begin{array}{c}\text { Độ ẩm } \\
\text { không } \\
\text { khí } \\
(\%)\end{array}$} & \multirow[t]{2}{*}{$\begin{array}{c}\text { Bốc hơi } \\
\text { nước } \\
\text { (mm/ngày) }\end{array}$} \\
\hline & $B$ & $\mathrm{~L}$ & & $\mathrm{~T}_{\min }$ & $\mathrm{T}_{\max }$ & & & & \\
\hline 1 & \multicolumn{2}{|c|}{2} & 3 & \multicolumn{2}{|c|}{4} & 5 & 6 & 7 & 8 \\
\hline 1. Bắc Ninh & $21^{0} 11$ & $106^{\circ} 05^{\prime}$ & 3 & 13.0 & 25.1 & 4 & 9.3 & 72 & 3.4 \\
\hline 2. Bắc Giang & $21^{017}$ & $106^{\circ} 12^{\prime}$ & 7 & 12.4 & 25.7 & 3 & 9.2 & 73 & 2.9 \\
\hline 3. Vĩnh Yên & $21^{0} 19$ & $105^{\circ} 36^{\prime}$ & 17 & 13.1 & 25.1 & 3 & 8.8 & 76 & 2.4 \\
\hline 4. Tam Đảo & $21^{\circ} 28$ & $105^{\circ} 39^{\prime}$ & 685 & 10.0 & 18.1 & 7 & 9.6 & 59 & 3.5 \\
\hline 5.Thái Nguyên & $21^{0} 36$ & $105^{\circ} 50^{\prime}$ & 36 & 11.5 & 25.2 & 4 & 8.6 & 72 & 3.1 \\
\hline 6. Bắc Kạn & $22^{\circ} 09$ & $105^{\circ} 50^{\prime}$ & 138 & 8.5 & 24.8 & 3 & 7.9 & 80 & 2.4 \\
\hline
\end{tabular}


mô tả bằng biểu thức:

$$
\begin{aligned}
R_{n i}=R_{n s} & +R_{n l} \equiv\left[(1-\alpha) R_{s}\right]+ \\
& +\left[R_{L}^{\downarrow}-R_{L}^{\uparrow}-\left(1-\varepsilon_{0}\right) R_{L}^{\downarrow}\right]
\end{aligned}
$$

Trong đó: $R_{S_{\downarrow}}$ - tia tới sóng ngắn $\left(W / m^{2}\right)$; $\alpha R_{S \downarrow}$ - tia phản xạ sóng ngắn $\left(W / m^{2}\right) ; R_{L \downarrow}$ tia tới sóng dài $\left(\mathrm{W} / \mathrm{m}^{2}\right) ; \mathrm{R}_{\mathrm{L} \uparrow}$ - tia phát xạ sóng dài $\left(W / m^{2}\right) ;\left(1-\varepsilon_{0}\right) R_{L \downarrow}$ - tia phản xạ sóng dài $\left(\mathrm{W} / \mathrm{m}^{2}\right)$, - suất phản xạ (albedo);, hế số phát xạ bề mặt.

Theo Jackson, et al., 1983; Zhang \& Lemeur, $1995[4,8]$ bức xạ mặt trời tại thời điểm $i, R_{i}\left(\mathrm{~W} / \mathrm{m}^{2} / \mathrm{h}\right)$ là:

$$
R_{n i}=R_{\max \sin \left(\pi \cdot \frac{t}{D L}\right)}
$$

Trong đó: $R_{\max }$ - Bức xạ mặt trời vào giữa trưa (12h); $D L$ - Độ dài của ngày (từ thời điểm mặt trời mọc tới thời điểm mặt trời lặn); $t$ - khoảng thời gian bắt đầu từ lúc mặt trời mọc tới thời điểm $i$. Để tính lượng bức xạ trung bình ngày, chúng ta cần tính tích phân sau:

$$
R_{n d}=\int_{0}^{D L} R_{\max \sin \left(\pi \cdot \frac{t}{D L}\right)}=A \cdot R_{i}
$$

Trong đó $\mathrm{A}$ là hệ số. Tương tự, chúng ta sẽ tính cho bức xạ ròng theo nguyên lý của Jackson, et al., 1983; Zhang \& Lemeur, 1995[3].

\subsection{Xác định lượng bốc thoát hơi} nước theo Mô hình chỉ số cân bằng năng Iượng bức xạ bề mặt đơn giản S-SEBI (Simplified Surface Energy Balance Index)

Mô hình chỉ số cân bằng năng lượng bề mặt đơn giản (S-SEBI) được phát triển Roerink et al., 2000[8]. Bằng cách giả định rằng bức xạ toàn cầu và nhiệt độ không khí là ổn định, sự giải thích về điều kiện vật lý liên quan đến hệ số phản xạ bề mặt albedo và nhiệt độ trong cách tiếp cận của mô hình S-SEBI có thể đưa ra khi đặc tính của bề mặt với sự thay đổi trong cảnh ảnh giữa vùng tối/ẩm ướt và vùng khô/sáng của các điểm ảnh. Phần bay hơi tức thời $E T F$ được xác định dựa vào mối quan hệ tuyến tính giữa suất phân sai bề mặt (albedo) và nhiệt độ bề mặt nhỏ nhất và lớn nhất tương ứng với vùng ẩm ướt và khô, để phân vùng năng lượng sẵn có thành dòng năng lượng nhiệt cảm ứng và dòng năng lượng nhiệt ẩn. Ở đây, phần bay hơi $(E T F)$ được hạn chế bởi các vùng khô và ẩm ướt và công thức được xây dựng dựa vào mối quan hệ tuyến tính giữa hệ số phát xạ bề mặt albedo và nhiệt độ bề mặt được đưa ra như sau:

Trong đó:

$$
E T F=\frac{\left(T_{H}-T_{s}\right)}{\left(T_{H}-T_{L E}\right)}
$$

$T_{H}$ - nhiệt độ bề mặt tương ứng với điều kiện khô, đại diện cho dòng nhiệt ẩn nhỏ nhất (LEdry $=0$ ) và dòng năng lượng nhiệt cảm ứng lớn nhất (Hdry $=R n-G)$;

$T_{L E}$ - nhiệt độ bề mặt tương ứng với điều kiện ẩm, đại diện cho dòng nhiệt ẩn lớn nhất (LEwet $=(R n-G)$ ) và dòng năng lượng nhiệt cảm ứng nhỏ nhất $(H w e t=0)$ cho sự phản xạ bề mặt được thể hiện ở sơ đồ. (xem hình1)

Giá trị ETFi được tính toán từ công thức sau:

$$
E T F i=\frac{a_{H}-\mathbf{b}_{H} \alpha-T S}{a_{H}-a_{L E}-\left(b_{H}-b_{L E}\right) \alpha}
$$

Khi đó dòng nhiệt cảm ứng $\mathrm{H}$ và giá trị bốc thoát hơi nước tức thời $\lambda \mathrm{ET}$ thu được sử dụng năng lượng bức xạ dòng như sau:

$$
H=(1-E T F)\left(R_{n}-G\right)
$$

$$
\text { Và } \lambda \mathbf{E T}=\operatorname{ETF}\left(R_{n}-G\right)
$$

Giá trị bốc thoát hơi nước theo ngày ước tính theo công thức $S-S E B I$ dựa vào lý thuyết vật lý coi giá trị bốc hơi nước tức thời ETFi bằng giá trị bốc hơi nước theo ngày ETFd:

$$
E T F_{i}=E T F_{d}=\frac{\lambda \mathbf{E T}_{i}}{\left(R_{i}-G_{i}\right)}=\frac{\lambda \mathbf{E T}_{d}}{\left(R_{d}-G_{d}\right)}(8)
$$

Xem xét với điều kiện tổng mật độ dòng 


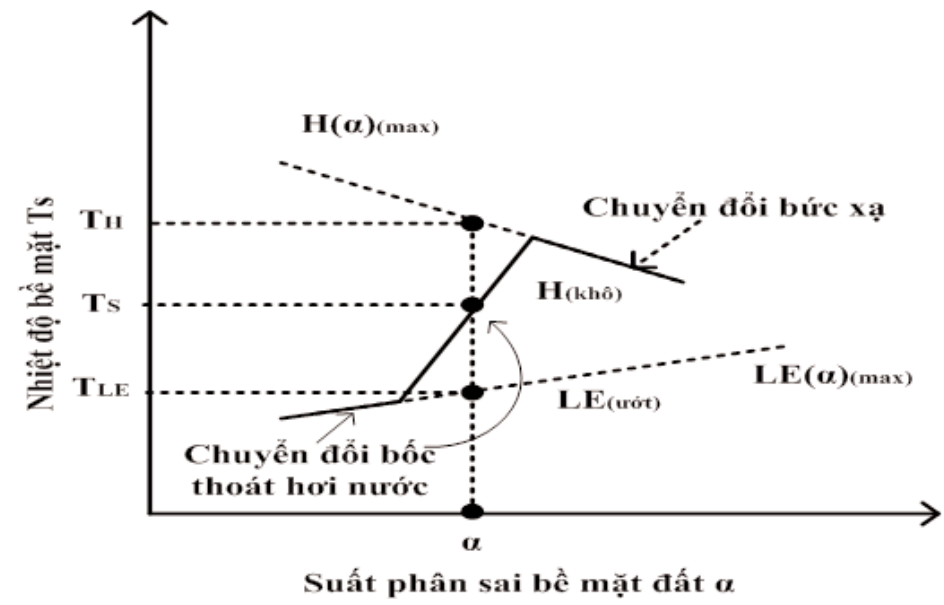

Hình 1: Sơ đồ mối quan hệ giữa nhiệt độ bề mặt và sự phản xạ bề mặt trong mô hình S-SEBI

nhiệt trong đất $(\mathrm{G})$ là xấp xỉ bằng không (theo Allen et al., 1998), giá trị bốc thoát hơi nước thực tế ETa được tính toán bởi công thức:

$$
E T a=\lambda \mathbf{E T}_{i} \frac{\mathbf{R}_{n d}}{\lambda \mathbf{R}_{n i}}
$$

\section{Thực nghiệm}

\subsection{Chiết tách năng lượng bức xạ} ròng trung bình ngày Rnd theo mô hình cân bằng năng lượng bức xạ bề mặt.

Áp dụng công thức (1), (2) và (3) tính bức xạ ròng trung bình ngày thời điểm ngày $04 / 11 / 2000$, và ngày $23 / 11 / 2001$ từ viễn thám sử dụng ảnh Landsat $R_{n d-V T}$ được ghi trong bảng 3 , cột 8 và bảng 4 , cột 8 (xem bảng 4) và Ảnh bức xạ ròng trung bình ngày cho hai thời điểm được trình bày ở hình $2 a$ và $2 b$. $R_{n d-V T}$ được tính dựa vào bức xạ ròng tức thời $R_{n i}$ (trung bình giờ) vào thời điểm thu nhận ảnh ngày 04/11/2000 (cột 2 , bảng 3), và ngày 23/11/2001 (cột 2, bảng 4); Góc giờ Mặt Trời $\omega_{\mathrm{s}}$ và độ dài của ngày $\mathrm{DL}$ từ lúc Mặt Trời mọc tới lúc Mặt Trời lặn là các đại lượng trung gian để xác định $R_{n d-V T}$ cũng được liệt kê ở bảng 3 và bảng 4 . (xem bảng 3 , bảng 4, hình 2)
4.2. Xác định lượng bốc thoát hơi nước theo Mô hình chỉ số cân bằng năng Iượng bức xạ bề mặt đơn giản S-SEBI (Simplified Surface Energy Balance Index)

Dựa vào mối quan hệ tuyến tính giữa nhiệt độ bề mặt Ts và suất phân sai bề mặt đất $\alpha$ (Albedo) chúng ta có thể xác định được hệ số lý thuyết phần bay hơi tức thời $E T F$ theo công thức (4). Áp dụng công thức (9) ước tính lượng bốc thoát hơi nước thực tế theo ngày từ ảnh viễn thám theo phương pháp chỉ số cân bằng năng lượng bức xạ bề mặt đơn giản S-SEBI. Trong nội dung nghiên cứu chia làm hai trường hợp tính bốc thoát hơi nước thực tế ETa; (1) khi chưa sử dụng mô hình số độ cao DEM để hiệu chỉnh nhiệt độ bề mặt đất Ts; (2) sau khi sử dụng mô hình số độ cao DEM để hiệu chỉnh nhiệt độ bề mặt đất Ts.

Đồ hình chọn đường biên xác định hệ số lý thuyết phần bay hơi tức thời từ mối quan hệ tuyến tính giữa nhiệt độ bề mặt và suất phân sai bề mặt đất $\alpha$ (Albedo) được mô tả trên hình $3 a$ và $3 b$. (xem hình 3 )

Các hệ số $a, b$ được xác định qua mối quan hệ giữa nhiệt độ Ts và suất phân sai bề mặt đất $\alpha$ (albedo) cho hai thời điểm ngày $04 / 11 / 2000$ và $23 / 11 / 2001$ được thể 


\section{Nghiên cúu - Úng dụng}

Bảng 3: Kết quả tính toán bức xạ ròng trung bình ngày 04/11/2000 theo mô hình viễn thám

\begin{tabular}{|l|c|c|c|c|c|c|c|}
\hline Trạm quan trắc & $\mathrm{R}_{\mathrm{ni}}\left(\mathrm{W} / \mathrm{m}^{2}\right)$ & $\omega_{\mathrm{s}}$ (độ) & $\omega_{\mathrm{s}}$ (radian) & $\begin{array}{c}\mathrm{DL} \\
(\mathrm{giờ}=\mathrm{h})\end{array}$ & $\begin{array}{c}2 \mathrm{DLR} \\
\left(\mathrm{W} / \mathrm{m}^{2}\right)\end{array}$ & $\begin{array}{c}\text { Hệ số } \mathrm{A} \\
(-)\end{array}$ & $\begin{array}{c}\mathrm{R}_{\mathrm{nd}}-\mathrm{VT} \\
\left(\mathrm{MJ} / \mathrm{m}^{2} / \mathrm{d}\right)\end{array}$ \\
\hline \multicolumn{1}{|c|}{ 1 } & 2 & 3 & 4 & 5 & 6 & 7 & 8 \\
\hline 1. Bắc Ninh & 443.356 & 83.42798 & 1.455355 & 11.44809 & 9858.544 & 7.135611 & 11.39 \\
\hline 3. Vĩnh Yiang & 445.472 & 83.39353 & 1.454754 & 11.1135 & 9901.505 & 7.131534 & 11.44 \\
\hline 4. Tam Đảo & 462.008 & 83.3818 & 1.454549 & 11.11194 & 10267.61 & 7.13015 & 11.86 \\
\hline 5.Thái Nguyên & 564.291 & 83.33 & 1.453646 & 11.10503 & 12532.94 & 7.124048 & 14.47 \\
\hline 6. Bắc Kạn & 487.688 & 83.28398 & 1.452843 & 11.0989 & 10825.6 & 7.118648 & 12.50 \\
\hline
\end{tabular}

Bảng 4: Kết quả tính toán bức xạ ròng trung bình ngày 23/11/2001 theo mô hình viễn thám

\begin{tabular}{|c|c|c|c|c|c|c|c|}
\hline an trắc & $\mathrm{R}_{\mathrm{ni}}\left(\mathrm{W} / \mathrm{m}^{2}\right)$ & $\omega_{\mathrm{s}}$ (độ) & $\omega_{\mathrm{s}}$ (radian) & $\begin{array}{c}\mathrm{DL} \\
(\text { giờ }=\mathrm{h})\end{array}$ & $\begin{array}{l}2 \mathrm{DLR}_{\mathrm{ni}} \\
\left(\mathrm{W} / \mathrm{m}^{2}\right)\end{array}$ & $\begin{array}{c}\text { Hệ số A } \\
(-)\end{array}$ & $\begin{array}{c}R_{n d}-V T \\
\left(M J / m^{2} / d\right)\end{array}$ \\
\hline 1 & 2 & 3 & 4 & 5 & 6 & 7 & 8 \\
\hline 1. Bắc Ninh & 418.736 & 81.5688 & 1.422922 & 10.87032 & 9103.592 & 6.932103 & 10.45 \\
\hline 2. Bắc Giang & 397.08 & 81.52454 & 1.42215 & 10.86443 & 8628.092 & 6.927673 & 9.91 \\
\hline 3. Vĩnh Yên & 427.1738 & 81.50947 & 1.421887 & 10.86242 & 9280.264 & 6.92617 & 10.65 \\
\hline 4. Tam Đảo & 493.569 & 81.44292 & 1.420727 & 10.85355 & 10713.95 & 6.919555 & 12.29 \\
\hline 5.Thái Nguyê & 442.416 & 81.38379 & 1.419695 & 10.84567 & 9596.596 & 6.913715 & 11.02 \\
\hline 6. Bắc Kạn & 431.377 & 81.138 & 1.415407 & 10.81291 & 9328.885 & 6.889815 & 10.07 \\
\hline
\end{tabular}

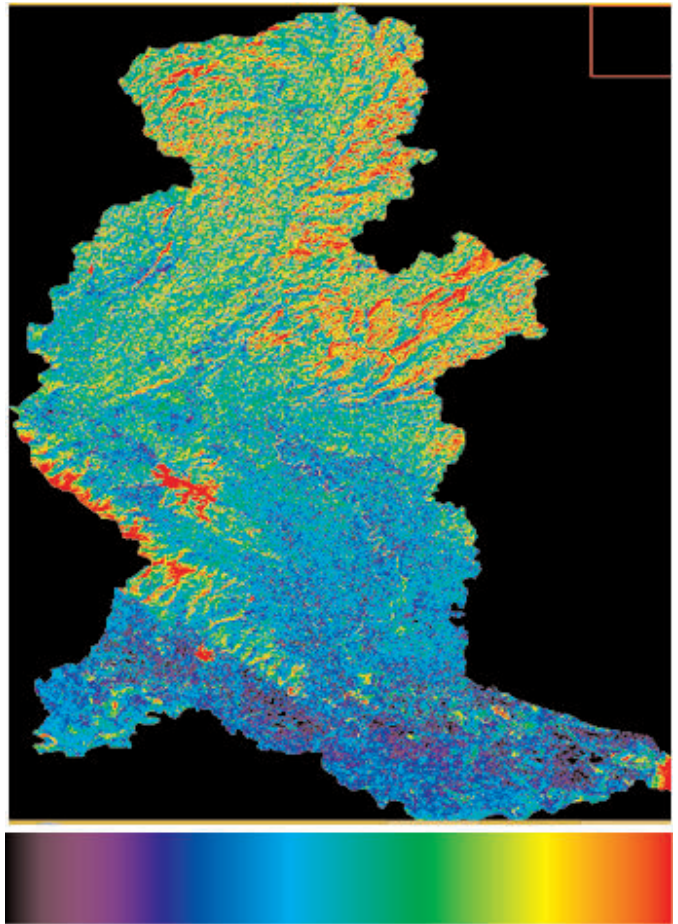

Hình 2a: Bức xạ ròng trung bình ngày 04/11/2000 chiết xuất từ ảnh Landsat-7 ( $\left.\mathrm{MJ} / \mathrm{m}^{2} / n g a ̀ y\right)$

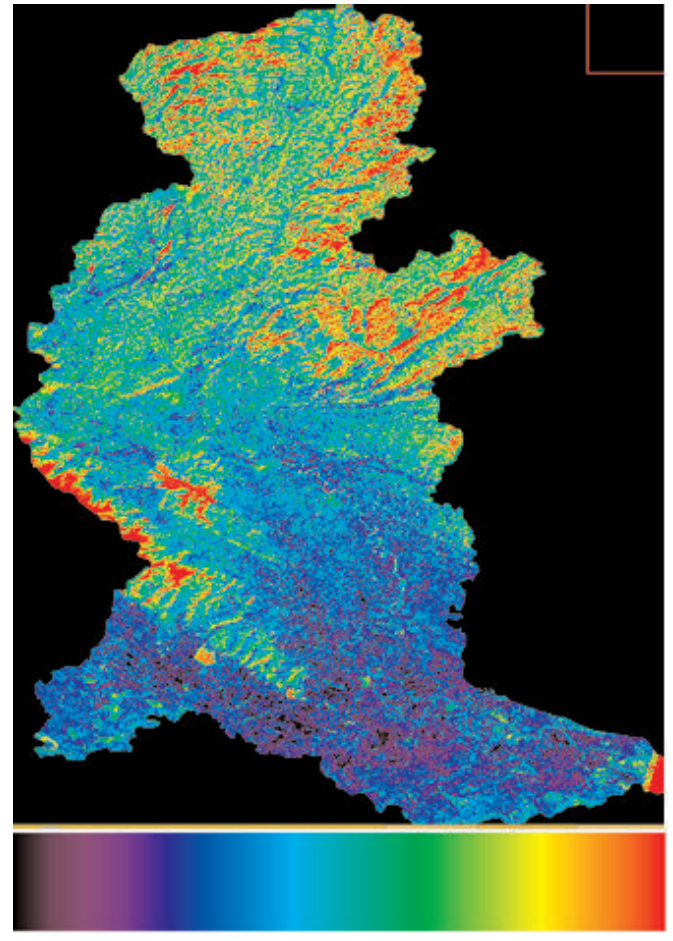

Hình 2b: Búpc xạ ròng trung bình ngày 23/11/2001 chiết xuất từ ảnh Landsat-7 ( $\left.\mathrm{MJ} / \mathrm{m}^{2} / \mathrm{ngày}\right)$ 


\section{Nghiên cúu - Úng dụng}

Bảng 5: Mối quan hệ giữa nhiệt độ Ts và suất phân sai bề mặt đất $\alpha$ (albedo) ngày 04/11/ 2000 và ngày 23/11/2001

\begin{tabular}{|c|c|c|c|c|}
\hline \multirow{2}{*}{ Mối tươny yuu.' } & \multicolumn{2}{|c|}{ Các hệ số [ngày 04/11/2000] } & \multicolumn{2}{c|}{ Các hệ số [ngày 23/11/2001] } \\
\cline { 2 - 5 } & $\mathbf{a}$ & $\mathbf{b}$ & $\mathbf{a}$ & $\mathbf{b}$ \\
\hline $\mathbf{T}_{H}$ & 46.45 & -42.20 & 36.52 & -31.10 \\
\hline $\mathbf{T}_{L E}$ & 16.39 & -36.33 & 12.84 & 28.95 \\
\hline
\end{tabular}

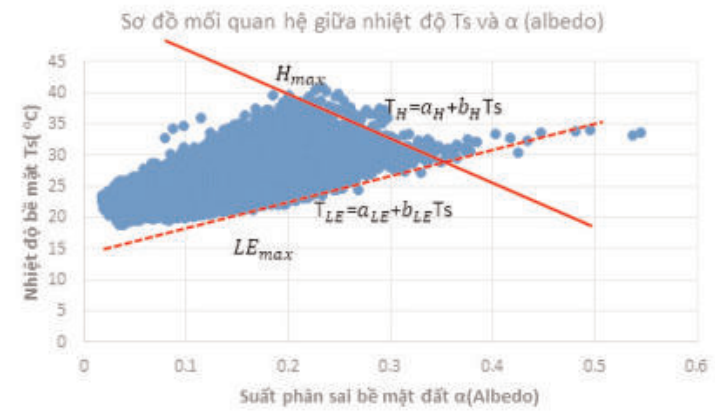

Hình 3a: Biểu đồ mô tả mối quan hệ giữa nhiệt độ Ts và Suất phân sai bề mặt đất $\alpha$ ngày 04/11/2000

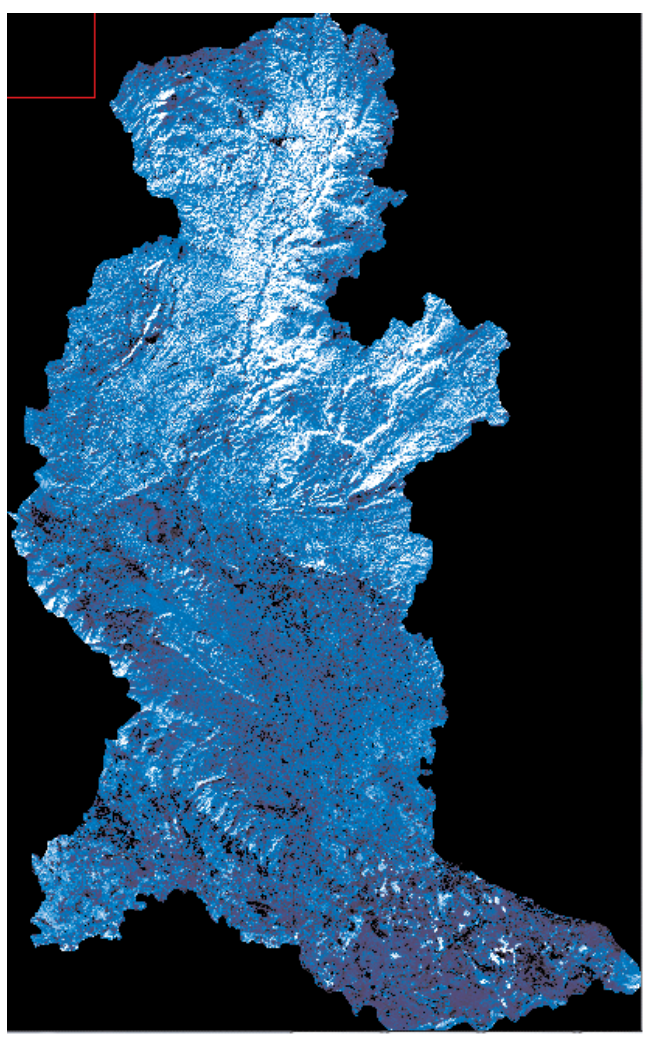

Hình 4a: Bốc thoát hơi nước thực tế ETa ( $\mathrm{mm} / \mathrm{ngày}$ ) thời điểm ngày 04/11/2000

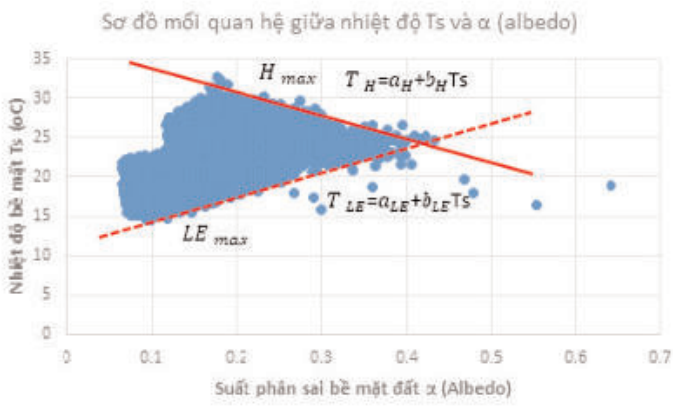

Hình 3b: Biểu đồ mô tả mối quan hệ giữa nhiệt độ Ts và Suất phân sai bề mặt đất a ngày 23/11/2001

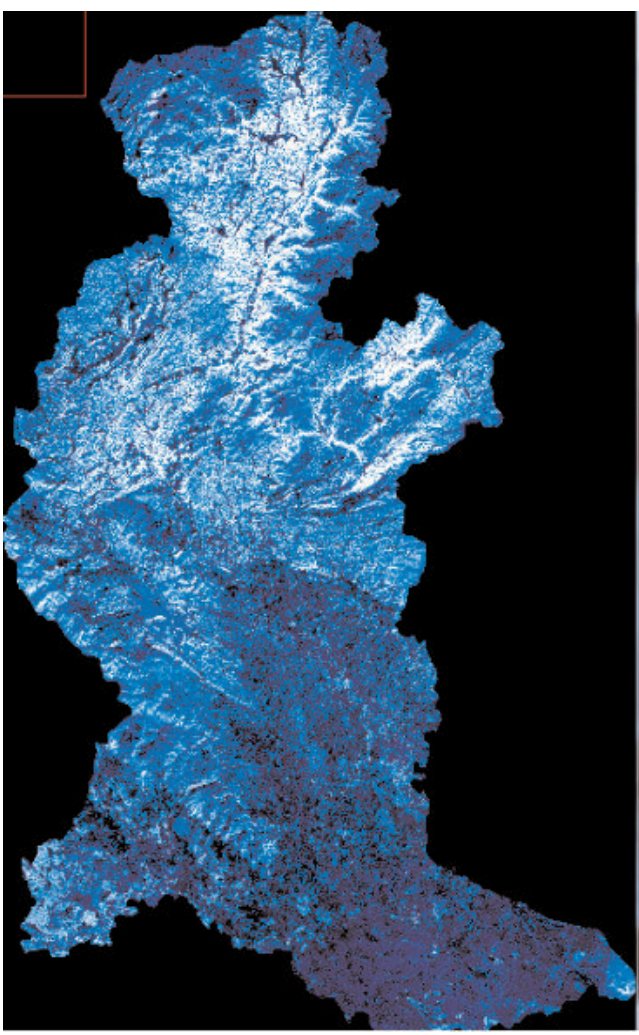

Hình 4b: Bốc thoát hơ nước thực tế ETa ( $\mathrm{mm} / \mathrm{ngày}$ ) thời điểm ngày 23/11/2001 
Bảng 6: Bảng đánh giá độ chính xác xác định Eta trung bình ngày 04/11/2000

\begin{tabular}{|l|c|c|c|c|c|c|}
\hline \multicolumn{1}{|c|}{ Trạm quan trắc } & $\begin{array}{c}\text { Rnd } \\
\left(\mathrm{MJ} / \mathrm{m}^{2} /\right. \\
\mathrm{ngày})\end{array}$ & $\begin{array}{c}\text { ETFi } \\
(\mathrm{mm} / \mathrm{ngày})\end{array}$ & $\begin{array}{c}\text { ETa-VT1 } \\
(\mathrm{mm} / \mathrm{ngày})\end{array}$ & $\begin{array}{c}\text { ETa-VT2 } \\
(\mathrm{mm} / \mathrm{ngày})\end{array}$ & $\begin{array}{c}\text { ETa-TĐ } \\
(\mathrm{mm} / \mathrm{ngày})\end{array}$ & $\begin{array}{c}\text { Sai số TB } \\
(\mathrm{mm} / \mathrm{ngày})\end{array}$ \\
\hline \multicolumn{1}{|c|}{1} & 2 & 3 & 4 & 5 & 6 & $7=6-5$ \\
\hline 1.Bắc Ninh & 11.87 & 0.7881 & 3.83 & 3.82 & 4.9 & 1.08 \\
\hline 2.Bắc Giang & 10.29 & 0.5421 & 2.28 & 2.28 & 3.9 & 1.62 \\
\hline 3.Vĩnh Yên & 11.50 & 0.6435 & 4.01 & 3.02 & 3.1 & 0.08 \\
\hline 4.Tam Đảo & 13.92 & 0.8211 & 4.86 & 4.66 & 4.3 & -0.36 \\
\hline 5.Thái Nguyên & 11.89 & 0.6984 & 3.03 & 3.39 & 4.4 & 1.01 \\
\hline 6.Bắc Kạn & 12.02 & 0.6423 & 3.18 & 3.15 & 2.8 & -3.35 \\
\hline Trung bình & & & 3.53 & 3.39 & 3.9 & \\
\hline Sai số TP $(\mathrm{mm} /$ ngày) & & & 1.07 & 0.92 & & \\
\hline Sai số TĐTB & & & $25.26 \%$ & $19.27 \%$ & & \\
\hline
\end{tabular}

Bảng 7: Bảng đánh giá độ chính xác xác định Eta trung bình ngày 23/11/2001

\begin{tabular}{|l|c|c|c|c|c|c|}
\hline \multicolumn{1}{|c|}{ Trạm quan trắc } & $\begin{array}{c}\text { Rnd } \\
\left(\mathrm{MJ} / \mathrm{m}^{2} /\right. \\
\mathrm{ngày})\end{array}$ & $\begin{array}{c}\text { ETFi } \\
(\mathrm{mm} / \mathrm{ngày})\end{array}$ & $\begin{array}{c}\text { ETa-VT1 } \\
(\mathrm{mm} / \mathrm{ngày})\end{array}$ & $\begin{array}{c}\text { ETa-VT2 } \\
(\mathrm{mm} / \mathrm{ngày})\end{array}$ & $\begin{array}{c}\text { ETa-TĐ } \\
(\mathrm{mm} / \mathrm{ngày})\end{array}$ & $\begin{array}{c}\text { Sai số TB } \\
(\mathrm{mm} / \mathrm{ngày})\end{array}$ \\
\hline \multicolumn{1}{|c|}{1} & 2 & 3 & 4 & 5 & 6 & $7=6-5$ \\
\hline 1.Bắc Ninh & 10.43 & 0.6154 & 2.67 & 2.62 & 3.4 & 1.08 \\
\hline 2.Bắc Giang & 9.89 & 0.4616 & 2.37 & 1.86 & 2.9 & 1.62 \\
\hline 3.Vĩnh Yên & 10.64 & 0.5534 & 2.89 & 2.40 & 2.4 & 0.08 \\
\hline 4.Tam Đảo & 12.29 & 0.7320 & 4.11 & 3.67 & 3.5 & -0.36 \\
\hline 5.Thái Nguyên & 11.02 & 0.6773 & 2.96 & 3.05 & 3.1 & 1.01 \\
\hline 6.Bắc Kạn & 10.74 & 0.6179 & 2.57 & 2.71 & 2.4 & -3.35 \\
\hline Trung bình & & & 2.93 & 2.72 & 2.9 & \\
\hline Sai số TP (mm/ngày) & & & 0.50 & 0.55 & & \\
\hline Sai số TĐTB & & & $15.06 \%$ & $13.29 \%$ & & \\
\hline
\end{tabular}

Biểu đồ bốc thoát hơi nước thực tế trên 06 trạm quan trắc thời điểm ngày $04 / 11 / 2000$

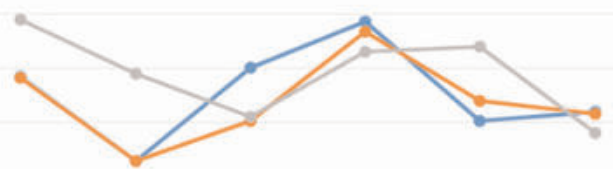

06 Trạm quan trắc

$\rightarrow$ ETa-VI1 $\rightarrow$ ETa-VIz $\rightarrow$ ETa-TD

Hình 5a: Biểu đồ bốc thoát hơ nước ngày 04/11/2000
Biếu đồ bốc thoát hơi nước thực tế trên 06 trạm quan trắc thời điểm ngày 23/11/2001

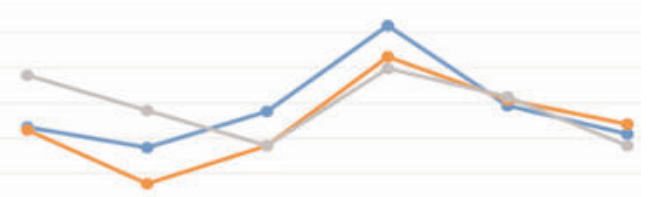

06 Trạm quan trắc

$\rightarrow$ ETa-VT1 $\rightarrow$ ETa-VI2 $\rightarrow$ ETa-TD

Hình 5b: Biểu đồ bốc thoát hơi nước ngày 23/11/2001 
hiện ở bảng 5. (xem bảng 5)

Sau khi xác định được các hệ số $a, b$ thay vào công thức (5), chúng ta xác định được phần bay hơi tức thời ETFi cho hai thời điểm ngày $04 / 11 / 2000$ và ngày 23/11/2001. Coi thông nhiệt bề mặt đất $G$ tính theo ngày bằng không (Allen et al, 1998) ta tính được lượng bốc thoát hơi nước thực tế theo ngày $\mathrm{ETa}$ ( $\mathrm{mm} /$ ngày) cho hai thời điểm ngày $04 / 11 / 2000$ và ngày 23/11/2001 được trình bày ở hình $4 a$ và hình 4b (xem hình 4). Bảng kết quả tính toán và biểu đồ lượng bốc thoát hơi nước tại 06 điểm quan trắc chiết xuất trên ảnh so sánh đánh giá với số liệu đo đạc bốc thoát hơi nước thực tế $\mathrm{ETa}$ TĐ đo bằng thiết bi chậu Pan ngoài thực địa với các sai số trung phương (SSTP), và sai số tuyệt đối trung bình (SSTĐTB) cho hai thời điểm được trình bày ở cột 4,5 bảng 6 , và cột 4,5 bảng 7 và hình $5 \mathrm{a}$ và hình $5 \mathrm{~b}$. (xem hình 5 , bảng 6 , bảng 7)

\section{Kết luận}

Qua kết quả nghiên cứu và tính toán bốc thoát thực tế ETa (mm/ngày) trung bình ngày theo Mô hình chỉ số cân bằng năng lượng bức xạ bề mặt đơn giản S-SEBI từ bức xạ ròng trung bình ngày chiết xuất từ ảnh Landsat rút ra một số nhận xét như sau:

- Ứng dụng tư liệu viễn thám cho phép chúng ta chiết xuất được lượng bốc thoát hơi nước thực tế Eta ( $\mathrm{mm} / \mathrm{ngày})$ của bề mặt địa hình trên quy mô diện rộng, nhanh và hiệu quả về kinh tế, đảm bảo cho công tác quy hoạch, quản lý và sử dụng nguồn tài nguyên nước.

- Sử dụng Mô hình chỉ số cân bằng năng lượng bức xạ bề mặt đơn giản (S-SEBI) ước tính bốc thoát hơi nước thực tế trung bình ngày ETa (mm/ngày) tại lưu vực Sông Cầu với sai số tuyệt đối trung bình nhỏ hơn $20 \%$ (sai số tuyệt đối trung bình theo phần trăm lần lượt là $13.29 \%$ cho thời điểm ngày $23 / 11 / 2001$ và $19.27 \%$ cho thời điểm ngày
04/11/2000)

- Sử dụng mô hình số độ cao DEM để hiệu chỉnh nhiệt độ bề mặt Ts cho khu vực vùng núi cao có thể nâng cao độ chính xác xác định lượng bốc thoát hơi nước thực tế ETa ( $\mathrm{mm} / \mathrm{ngày})$. Kết quả thực nghiệm xác định lượng bốc thoát hơi nước thực tế $\mathrm{ETa}$ tại lưu vực Sông Cầu sau khi hiệu chỉnh nhiệt độ bề mặt Ts bởi DEM độ chính xác định bốc thoát hơi nước thực tế đã tăng thêm $6 \%$ cho thời điểm ngày $04 / 11 / 2000$ và tăng thêm $2 \%$ cho thời điểm ngày 23/11/2001.

- Độ chính xác xác định lượng bốc thoát hơi nước thực tế sử dụng Mô hình chỉ số cân bằng năng lượng bức xạ bề mặt đơn giản S-SEBI phụ thuộc kinh nghiệm của người chọn đường thẳng tuyến tính giữa nhiệt độ Ts và suất phân sai bề mặt đất albedo.

Trong tương lai nhóm nghiên cứu sẽ tiến hành khảo sát mối liên hệ giữa bốc thoát hơi nước thực tế ETa và bốc thoát hơi nước tham chiếu ETo với chỉ số thực vật NDVI và từ đó xác định hệ số cây trồng Kc từ các mối liên hệ này. $O$

\section{Tài liệu tham khảo}

[1]. Bastiaanssen WGM, Menenti M, Feddes RA, Holtslag AAM. A remote sensing surface energy balance algorithm for land (SEBAL) 1. Formulation. J Hydrol (1998); 212-213:198-212.

[2]. Bastiaanssen, W.G.M.; Pelgrum, H.; Wang, J.; Ma, Y.; Moreno, J.F.; Roerink, G.J.; van der Wal, T. A remote sensing surface energy balance algorithm for land (SEBAL): 2. Validation. J. Hydrol.1998, 212-213, 213-229.

(Xem tiếp trang 54) 